\section{Preoperative naproxen sodium reduces postoperative pain following arthroscopic knee surgery}

William E. Code MD FRCPC, Raymond W. Yip MD FRCPC, Michael E. Rooney BSP MD, Philip M. Browne BSc MD, Tomas Hertz
This study was undertaken to assess the efficacy of a single preoperative dose of naproxen sodium in reducing postoperative pain and length of day surgery stay in patients undergoing arthroscopic knee surgery. A randomized, double-blind clinical trial was carried out on 66 ASA I and ASA II patients scheduled for arthroscopic knee surgery. The treatment group ( $n=$ 26) received two capsules containing $275 \mathrm{mg}$ of naproxen sodium each, and the control group $(n=40)$ received placebo. Preoperative and postoperative visual analogue pain scores, postoperative analgesic requirements in hospital as well as 24 hr afier discharge, and length of day surgery stay were studied. There was a decrease in postoperative pain, both in hospital (naproxen $0.7 \pm 1.2$ vs placebo $2.2 \pm 2.3$ ) and at $24 \mathrm{hr}$ afier discharge (naproxen $0.8 \pm 1.9$ vs placebo $3.8 \pm 3.2)(P=$ 0.0001 ). There was no difference in the need for in-hospital postoperative analgesics or in the time to discharge. However, there was a difference in the use of analgesics after discharge (naproxen group $30.4 \%$ vs placebo group $71.4 \%)(P<0.01$ ). The results of this study suggest that a single preoperative dose of $550 \mathrm{mg}$ naproxen sodium is effective in reducing postoperative pain in arthroscopic knee surgery, both in the immediate postoperative period and for up to $24 \mathrm{hr}$ after the completion of surgery.

\section{Key words}

ANAESTHESIA: outpatient;

ANALGESICS: naproxen;

PAIN: postoperative;

PREMEDICATION:

SURGERY: arthropaedic.

From the Department of Anaesthesia, Royal University

Hospital, Saskatoon, Saskatchewan.

Address correspondence to: Dr. Raymond W. Yip,

Department of Anaesthesia, Royal University Hospital,

Saskatoon, Saskatchewan S7N 0X0.

Accepted for publication 6th October, 1993.
Cette étude vise à évaluer l'efficacité d'une dose préopératoire unique de naproxène sodique administrée pour diminuer la douleur postopératoire et la durée du séjour hospitalier en chirurgie d'un jour chez des patients qui subissent une chirurgie arthroscopique du genou. Une étude randomisée et à double insu est réalisée chez 66 ASA I et ASA II programmés pour une chirurgie du genou par arthroscopie. Chaque membre du groupe traitement $(n=26)$ reçoit deux capsules contenant 275 mg de naproxène sodique alors que le groupe contrôle $(n=$ 40) reçoit un placébo. Des échelles visuelles analogues pré- et postopératoire, les besoins analgésiques postopératoires et la durée du séjour font l'objet de l'étude. Lintensité de la douleur postopératoire diminue aussi bien à lhôpital (naproxène 0,7 $\pm 1,2$ vs placébo $2,2 \pm 2,3$ ) que 24 h après le congé (naproxène $0,8 \pm 1,9$ vs placébo 3,8 $\pm 3,2 ; P=0.001$ ). Quant au besoin d'analgésiques postopératoires, on ne trouve pas de différence pendant le séjour hospitalier ou au moment du congé. Cependant, on note une différence pour l'utilisation d'analgésiques après le congé (naproxène $30,4 \%$ vs plaébo $71,4 \%, P<0,01$ ). Les résultats de cette étude suggèrent l'efficacité d'une seule dose préopératoire de $550 \mathrm{mg}$ de naproxène sodique pour réduire la douleur postopératoire en chirurgie arthroscopique du genou dans la période postopératoire immédiate et jusqu'à 24 h après la complétion de la chirurgie.

Arthroscopic surgery is one of the most commonly performed orthopaedic procedures, and is promoted as offering many advantages over open surgical procedures, including less patient discomfort and pain, shorter hospitalization, and quicker rehabilitation.' There are few reports of pain after arthroscopic procedures. ${ }^{2}$ However, previous studies have suggested that non-steroidal antiinflammatory drugs (NSAIDS) may decrease the inflammation associated with arthroscopic procedures, probably due to the inhibition of prostaglandin synthesis, thus reducing pain and speeding recovery. ${ }^{3}$ To evaluate the role of prostaglandins in post-arthroscopy pain, several studies have evaluated the use of the anti-prostaglandin nonsteroidal anti-inflammatory drugs in reducing arthros- 
copy related pain. ${ }^{3-6}$ These studies evaluated the effectiveness of NSAIDS administered postoperatively in multiple doses. This study was undertaken to assess the efficacy of a single preoperative dose of the NSAID naproxen sodium (Anaprox ${ }^{\circledR}$, Syntex) as a means of reducing postoperative pain and length of day surgery stay in patients undergoing arthroscopic knee surgery.

\section{Methods}

All ASA I and II patients scheduled for arthroscopic knee surgery in the day surgery units at St. Paul's, City, and Royal University hospitals in Saskatoon were considered for study. The study protocol was approved by the University of Saskatchewan advisory committee on ethics in human experimentation and the administration of each hospital. Patients with a history of peptic ulcer disease, adverse reaction to any non-steroidal antiinflammatory agents, bleeding disorders, or use of narcotic, NSAID or other analgesic agents up to the time of their procedure were excluded from the study.

All eligible patients were interviewed and had the study explained to them. Those who consented to participate in the study provided written informed consent and were randomized to one of two groups, receiving either two capsules containing $275 \mathrm{mg}$ naproxen sodium or two capsules containing lactose. The capsules were randomized by the department of pharmacy in a single lot of 100 . The active drug was Anaprox ${ }^{\circledR} 275 \mathrm{mg}$ tablets (Syntex Inc., Mississauga, Ont.), which were crushed and then reformulated into capsules to allow for the manufacture of placebo capsules identical in appearance and weight.

After being randomized to a study group in a doubleblind fashion, the patients were asked to indicate their level of pain on a $10 \mathrm{~cm}$ visual analogue pain scale as a baseline measurement for subsequent postoperative pain assessment. The capsules corresponding to the patient's randomization number were then administered orally 30-60 min before surgery.

No other medications were administered before anaesthesia and surgery. The arthroscopy was carried out under either general or local anaesthesia, with the agents used left to the discretion of individual anaesthetists, including the use of intraoperative opioids as desired. In those patients where intraoperative opioids were used, they were limited to either fentanyl $1 \mu \mathrm{g} \cdot \mathrm{kg}^{-1}$ or alfentanil $10 \mu \mathrm{g} \cdot \mathrm{kg}^{-1}$ administered at induction. Anaesthesia was induced with thiopentone or propofol, and maintained with $\mathrm{N}_{2} \mathrm{O} / \mathrm{O}_{2}$ and isoflurane or halothane. Local anaesthesia consisted of skin infiltration with $1 \%$ lidocaine and intra-articular $1 \%$ lidocaine $\mathrm{CO}_{2}$. No intraarticular narcotics were utilized.

After the completion of the procedure, the patient's pain was assessed on the same $10 \mathrm{~cm}$ visual analogue pain scale once or twice before discharge from the day surgery unit. An attempt. was made to assess pain one and two hours after the completion of the procedure, but the actual times varied due to differences in time to discharge from the recovery room and in time to recovery from anaesthesia sufficient to allow completion of the pain score. Those who had only one postoperative pain assessment were a small minority who were discharged after being assessed once. The patient's postoperative analgesic requirements, and the times from the end of surgery to discharge from both the recovery room and the day surgery unit were also reconded. As well, patients were provided with a $10 \mathrm{~cm}$ visual analogue pain scale at discharge, on which were marked $1 \mathrm{~cm}$ increments. They were contacted $24 \mathrm{hr}$ after their surgery, and were asked to draw a line on the pain scale, then to report verbally the position of their marking of this pain score.

The Chi-squared test and Wilcoxon rank sum test were used for statistical comparison of the groups, with $P<$ 0.05 considered significant.

\section{Results}

Eighty-four patients scheduled for arthroscopic knee surgery in the three study hospitals were considered for study. Of these, 17 were not enrolled, eight due to previous peptic ulcer disease, three due to previous adverse reaction to NSAIDs, two for personal reasons, two due to NSAID use up to the night before the procedure, one with a history of asthma, and one due to a history of bleeding problems (spontaneous epistaxis, gum bleeds). Thus 67 consenting patients were enrolled in the study. Of these, one was removed due to naproxen use both before and after the procedure which was disclosed at follow-up the day after surgery. A total of 66 patients completed the study; 40 received placebo, and 26 received $550 \mathrm{mg}$ naproxen sodium. There were no differences between the groups in terms of age, sex, weight, use of opioids during anaesthesia, baseline pain scores, nature of procedure (meniscectomy vs diagnostic arthroscopy), or type of anaesthetic used (Table I).

In patients receiving $550 \mathrm{mg}$ naproxen sodium, there was a significant decrease in pain scores at an average of $56 \mathrm{~min}$ postoperatively (pain score one hour) and at an average of $102 \mathrm{~min}$ postoperatively (pain score 2 hours) (Table II).

When analgesia was required postoperatively, it consisted of meperidine (two patients), morphine (one patient), or a combination of acetaminophen $300 \mathrm{mg}$, caffeine $15 \mathrm{mg}$, and codeine $30 \mathrm{mg}$ (11 patients). There was no difference between the groups in the need for postoperative analgesics while in the day surgery unit (Table III). 
TABLE I

\begin{tabular}{llll}
\hline & Placebo & $\begin{array}{l}\text { Naproxen } \\
\text { sodium }\end{array}$ & $P$ \\
\hline Age (yr) & $36.6 \pm 12.2$ & $38.8 \pm 10.9$ & NS \\
Weight (kg) & $80.5 \pm 17.1$ & $77.5 \pm 13.6$ & NS \\
Sex & $\mathrm{M}=22$ & $\mathrm{M}=22$ & $\mathrm{NS}$ \\
& $\mathrm{F}=18$ & $\mathrm{~F}=14$ & \\
$\begin{array}{l}\text { Opioids received during } \\
\quad \text { anaesthesia }\end{array}$ & $19 / 40(48 \%)$ & $14 / 26(54 \%)$ & $\mathrm{NS}$ \\
Meniscectomy & $29 / 40(72 \%)$ & $18 / 26(69 \%)$ & $\mathrm{NS}$ \\
Diagnostic arthroscopy & $11 / 40(28 \%)$ & $8 / 26(31 \%)$ & $\mathrm{NS}$ \\
\hline
\end{tabular}

Continuous variables are reported as means \pm standard deviation.

TABLE II

\begin{tabular}{lccl}
\hline & Placebo & $\begin{array}{l}\text { Naproxen } \\
\text { sodium }\end{array}$ & $P$ \\
\hline Pain score baseline & $0.11 \pm 0.6$ & $0.14 \pm 0.7$ & NS \\
& $(n=40)$ & $(n=26)$ & \\
Pain score one hour & $2.2 \pm 2.3$ & $0.7 \pm 1.2$ & 0.0001 \\
& $(n=40)$ & $(n=26)$ & \\
Pain score two hours & $2.4 \pm 2.2$ & $1.0 \pm 1.7$ & 0.0015 \\
& $(n=37)$ & $(n=17)$ & \\
Pain score 24 hr & $3.8 \pm 3.2$ & $0.8 \pm 1.9$ & 0.0001 \\
& $(n=35)$ & $(n=23)$ & \\
\hline
\end{tabular}

Means $\pm \mathrm{SD}$.

Fifty-eight patients were successfully contacted the day after surgery and interviewed with respect to analgesic consumption since discharge from hospital. Analgesics used were acetaminophen with or without codeine. Fewer patients in the naproxen sodium treated group reported using analgesics after discharge, $P<0.05$ (Table III).

There was also a decrease in the pain scores reported $24 \mathrm{hr}$ postoperatively (pain score 24 hours) (Table II). The time to discharge from the day surgery unit in the drug treated group was $91.8 \pm 49.1 \min (n=26)$, vs $98.5 \pm 54.4 \mathrm{~min}(n=40)$ for placebo, but this difference was not statistically significant.

\section{Discussion}

The results of this study suggest that a single preoperative dose of $500 \mathrm{mg}$ naproxen sodium is effective in reducing postoperative pain after arthroscopic knee surgery, both immediately after surgery and for up to $24 \mathrm{hr}$ after its completion. Effective postoperative analgesia may influence rehabilitation, ${ }^{7}$ and several studies have evaluated the efficacy of NSAIDs in improving the rate of recovery after surgery. Brown et al. ${ }^{7}$ compared the analgesic efficacy of postoperatively administered naproxen sodium, morphine sulfate, and placebo in 90 hospitalized patients with postoperative pain resulting from orthopaedic, general surgery, and gynaecological procedures. A single oral
TABLE III Patients requiring postoperative analgesics

\begin{tabular}{llll}
\hline & Placebo & $\begin{array}{l}\text { Naproxen } \\
\text { sodium }\end{array}$ & $P$ \\
\hline In day surgery unit & $11 / 40(28 \%)$ & $3 / 26(12 \%)$ & NS \\
Post discharge followup & $25 / 35(71 \%)$ & $7 / 23(30 \%)$ & $<0.01$ \\
\hline
\end{tabular}

dose of $550 \mathrm{mg}$ naproxen sodium was as effective at one hour as a single injectable dose of morphine $10 \mathrm{mg}$, and from three to six hours after dosing, naproxen sodium provided greater pain relief than either morphine or placebo. Similar studies by Ogilvie-Harris et al. ${ }^{5}$ comparing postoperative naproxen sodium with placebo in 139 patients undergoing arthroscopic meniscectomy showed that the active treatment group had less pain during activity at all times tested in the study.

Postoperative administration of naproxen sodium has also been evaluated in comparison with a combination of propoxyphene napsylate and acetaminophen for pain relief after arthroscopy or arthroscopic meniscectomy. ${ }^{4}$ The results of this study suggested that in the first six hours after surgery when these drugs were evaluated, pain intensity was lower at each hour in the naproxen sodium than in the propoxyphene-acetaminophen group, and significantly lower at one hour.

In contrast to this postoperative management of pain, the concept of pre-emptive analgesia has emerged from a better understanding of the mechanisms behind postoperative pain. Woolf and $\mathrm{Chang}^{8}$ reviewed the effects of peripheral tissue injury and its management. Two kinds of modification in the responsiveness of the nervous system occur with peripheral tissue injury. The first is peripheral sensitization, in which there is reduction in the threshold of nociceptor afferent peripheral nerves, and the second is central sensitization, which is an activitydependent increase in the excitability of spinal neurons. ${ }^{8}$

Peripheral tissue injury produces inflammatory pain which results from an increased sensitivity of highthreshold nociceptor neurons at their peripheral terminals when they are exposed to the inflammatory mediators and other chemicals released in reaction to tissue damage. ${ }^{8}$ Preventing this peripheral sensitization has been assumed to be the major action of NSAIDs by inhibition of prostaglandin production by the enzyme cyclooxygenase. ${ }^{9}$

The inflammatory reaction to tissue damaged during surgery may provide a source of postoperative sensory signals that could induce central sensitization. Thus if peripheral sensitization is decreased, central sensitization would be decreased and postoperative pain would be reduced.

The present study was undertaken to assess the effectiveness of preoperative administration of naproxen so- 
dium in reducing the peripheral sensitization to pain and presumably also central sensitization. Further support for this use of naproxen comes from a recent study by Comfort et al. ${ }^{10}$ which evaluated a similar use of naproxen sodium in tubal ligations. This study showed that preoperative naproxen sodium decreased postoperative tubal ligation pain and reduced postoperative analgesic requirements, with less time to street fitness, and no increase in analgesic-induced side effects.

Naproxen sodium possesses a very favourable pharmacokinetic profile for oral preoperative administration. It dissolves more rapidly in gastric juice and consequently produces earlier and higher plasma concentrations than naproxen. Peak plasma concentrations are achieved in about one hour with naproxen sodium compared with two hours for naproxen. "The elimination half-life of naproxen is about 12 to $15 \mathrm{hr}$ and appears to be independent of plasma concentration or dosage. ${ }^{11}$ Thus, it provides effective analgesia well into the postoperative period.

The antiplatelet action of NSAIDs may predispose patients to postoperative bleeding. However, this and other similar studies using NSAIDs have not detected problems with surgical bleeding (i.e., subjective increase in oozing from surgical sites postoperatively). 9,12

In summary, premedication with oral naproxen sodium prior to arthroscopic knee surgery is effective in reducing both postoperative pain and postoperative analgesic requirements. Naproxen sodium is recommended as an effective oral premedication for arthroscopic knee surgery.

\section{Acknowledgements}

The authors wish to thank Lenore McFarlane and Deb Meier for their expertise in preparing this manuscript.

\section{References}

1 Colville JM, Jackson DW. Reasonable expectations following arthroscopic surgery. Clin Sports Med 1985; 4: 279-93.

2 Jokl P, Warman M. A comparison of the efficacy and tolerability of diflunisal and dextropropoxyphene napsylate with acetaminophen in the management of mild to moderate pain after arthroscopy of the knee. Clin Ther 1989; 11 : 841-45.

3 Vander-Schilden JL. Improvements in rehabilitation of the postmenisectomized or meniscal repair patient. Clin Orth Rel Res 1990; 252: 73-79.

4 Drez D, Ritter M, Rosenberg TD. Pain relief after arthroscopy: naproxen sodium compared to propoxyphene napsylate with acetaminophen. S Med J 1987; 80: 440-43.

5 Ogilvie-Harris DJ, Bauer M, Corey P. Prostaglandin inhibition and the rate of recovery after arthroscopic meniscectomy. J Bone Joint Surg 1985; 67-B: 567-71.
6 Indelicato PA. Efficacy of diflunisal versus acetaminophen with codein in controlling mild to moderate pain after arthroscopy. Clin Ther 1986; 8: 164-69.

7 Brown $C R$, Sevelius $H$, Wild V. A comparison of single doses of naproxen sodium, morphine sulfate, and placebo in patients with postoperative pain. Cur Ther Res 1984; 35: 511-18.

8 Woolf CJ, Chong M.-S. Preemptive analgesia - treating postoperative pain by preventing the establishment of central sensitization. Anesth Analg 1993; 77: 362-79.

9 Dahl JB, Kehlet $H$. Non-steroidal anti-inflammatory drugs: rationale for use in severe postoperative pain. $\mathbf{B r} \mathbf{J}$ Anaesth 1991; 66: 703-12.

10 Comfort VK, Code WE, Rooney ME, Yip RW. Naproxen premedication reduces postoperative tubal ligation pain. Can J Anaesth 1992; 39: 349-52.

11 Todd PA, Clissold SP. Naproxen. A reappraisal of its pharmacology, and therapeutic use in rheumatic diseases and pain states. Drugs 1990; 40: 91-137.

12 Maunukseal E-L, Ryhänen P, Janhunen L. Efficacy of rectal ibuprofen in controlling postoperative pain in children. Can J Anaesth 1992; 39: 226-30. 